\title{
Publisher Correction: Structure-performance descriptors and the role of Lewis acidity in
} the methanol-to-propylene process

Irina Yarulina, Kristof De Wispelaere, Simon Bailleul, Joris Goetze (D), Mike Radersma, Edy Abou-Hamad, Ina Vollmer, Maarten Goesten, Brahim Mezari, Emiel J. M. Hensen (D, Juan S. Martínez-Espín, Magnus Morten, Sharon Mitchell, Javier Perez-Ramirez (D), Unni Olsbye, Bert M. Weckhuysen (D), Veronique Van Speybroeck (D), Freek Kapteijn and Jorge Gascon (iD

Correction to: Nature Chemistry https://doi.org/10.1038/s41557-018-0081-0, published online 25 June 2018.

In the version of this Article originally published, on the right side of Fig. 4b, the 'Aromatic cycle' label was erroneously shifted outside of the central circular arrow into a position on part of the reaction cycle. This has been corrected in the online versions of the Article.

Published online: 10 July 2018

https://doi.org/10.1038/s41557-018-0118-4 